NIST Technical Note 2047

\title{
Aqueous-based Amphiphile Solutions \\ Used as Gel Coatings to Reduce Flammability of Cotton Fabrics
}

\author{
Andre L. Thompson \\ Brian J. Love \\ Rick D. Davis
}


NIST Technical Note 2047

\title{
Aqueous-based Amphiphile Solutions Used as Gel Coatings to Reduce Flammability of Cotton Fabrics
}

\author{
Andre L. Thompson ${ }^{\mathrm{a}, \mathrm{b}}$ \\ Brian J. Love ${ }^{\mathrm{b}}$ \\ Rick D. Davis ${ }^{\mathrm{a}}$ \\ ${ }^{a}$ Fire Research Division \\ Engineering Laboratory \\ National Institute of Standards and Technology \\ ${ }^{\mathrm{b}}$ Department of Materials Science and Engineering \\ Department of Biomedical Engineering \\ University of Michigan
}

This publication is available free of charge from: https://doi.org/10.6028/NIST.TN.2047

July 2019

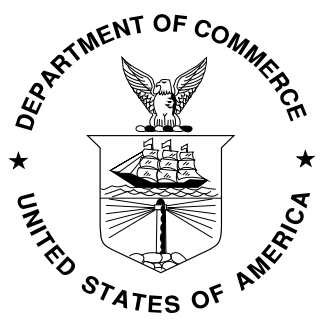

U.S. Department of Commerce Wilbur L. Ross, Jr., Secretary

National Institute of Standards and Technology Walter Copan, NIST Director and Undersecretary of Commerce for Standards and Technology 
Certain commercial entities, equipment, or materials may be identified in this document in order to describe an experimental procedure or concept adequately. Such identification is not intended to imply recommendation or endorsement by the National Institute of Standards and Technology, nor is it intended to imply that the Entities, materials, or equipment are necessarily the best available for the purpose.

National Institute of Standards and Technology Technical Note 2047

Natl. Inst. Stand. Technol. Tech. Note 2047, 26 pages (July 2019)

CODEN: NTNOEF

This publication is available free of charge from:

https://doi.org/10.6028/NIST.TN.2047 


\begin{abstract}
This study reports on the change in flammability of cotton fabrics caused by water-insoluble gel coatings applied from a single bath solution formulated with polymeric micelles and flame retardant amphiphiles. The flame resistant coatings are made from low concentration aqueous formulations of polyethylene oxide-polypropylene oxide-polyethylene oxide, and $5 \%$ to $15 \%$ mass fraction melamine and sodium hexametaphosphate. The coated cotton fabrics were tested and characterized by a variety of bench-scale tools, such as vertical flame testing, micro-scale combustion calorimetry, and thermogravimetric analysis. Properties such as increased ignition resistance, self-extinguishment, and higher decomposition temperatures were measured, relative to the uncoated cotton.
\end{abstract}

Keywords : amphiphilic solutions; cotton fabric; flame retardant gel coating; melamine; sodium hexametaphosphate. 


\section{Contents}

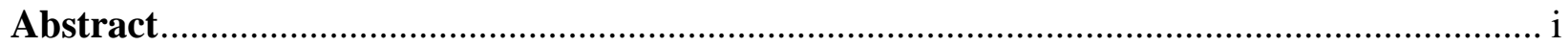

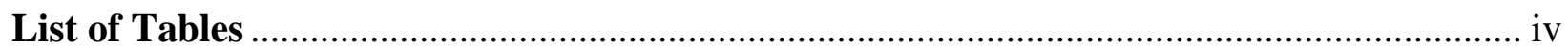

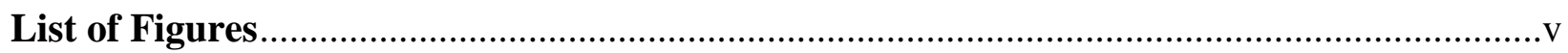

List of Acronyms and Abbreviations ............................................................................ vi

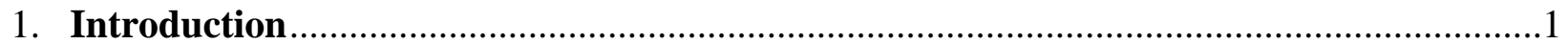

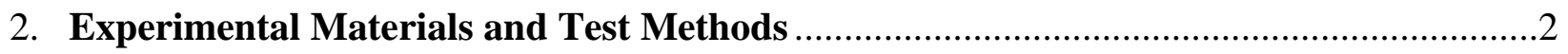

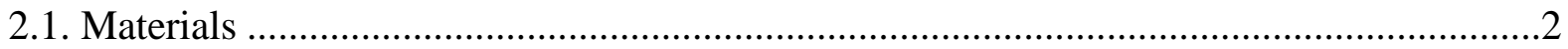

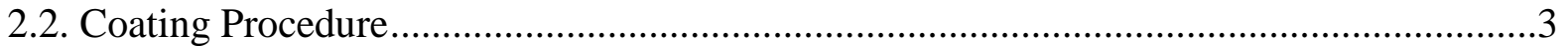

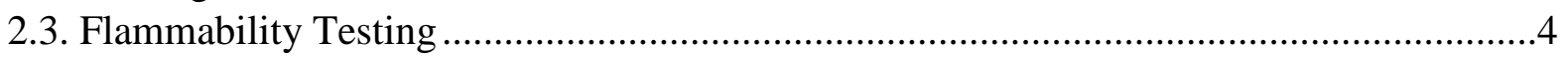

2.4 Morphological Characterization .........................................................................

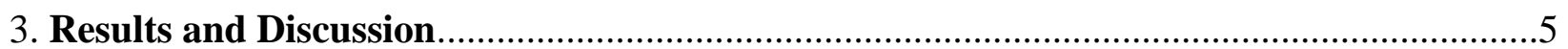

3.1. Fabrication and Flammability Screening .............................................................

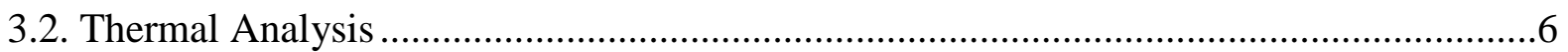

3.3. Comparison to Other Technologies ............................................................................. 11

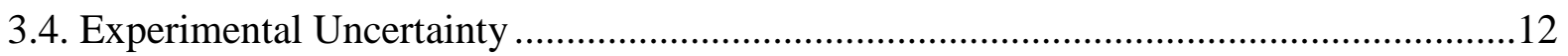

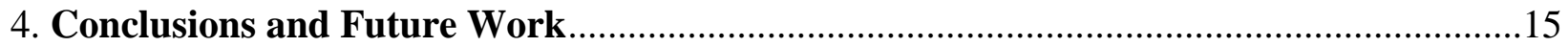

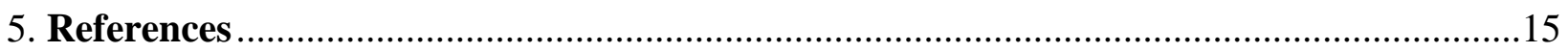




\section{List of Tables}

Table 1. Coating composition, mass gain \%, and open flame screening for flame retardant-coated cotton fabrics. Mass gain is reported with a $2 \sigma$ standard uncertainty ......................................6

Table 2. TGA properties of uncoated cotton fabric, melamine/SHMP on cotton, F127/melamine/SHMP gel coating on cotton, and F127/melamine/SHMP coating itself. Data is reported with a $2 \sigma$ standard uncertainty. The slopes correspond to the dehydration of the coated fabric (1) followed by the active combustion of the dehydrated composite (2) ...........................8

Table 3. Heat release properties of uncoated cotton fabric, melamine/SHMP on cotton, F127/melamine/SHMP gel coating on cotton, and F127/melamine/SHMP coating itself. Data represents the average of 3 replicates and is reported with a $2 \sigma$ standard uncertainty................10

Table 4. Uncertainty in full-scale experimental data.............................................................14 


\section{List of Figures}

Figure 1. (a) F127 (b) Schematic of PEO-PPO-PEO micelle structure (c) Sodium

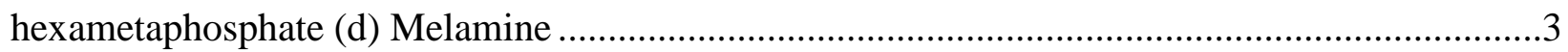

Figure 2. Schematic of vertical flame test (VFT) setup........................................................5

Figure 3. TGA data for F127/melamine/SHMP gel coating on cotton fabric (blue dots), melamine/SHMP (red solid line), uncoated cotton fabric (black dash-dots), and coating itself

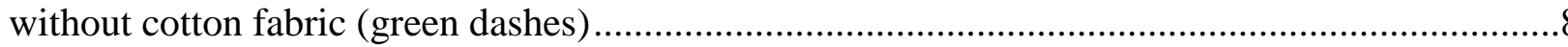

Figure 4. MCC results of (a) uncoated cotton fabric (black dash-dots) and melamine/SHMP (red solid line) (b) uncoated cotton fabric (black dash-dots) and F127/melamine/SHMP gel coating on cotton fabric (blue dots) (c) uncoated cotton fabric (black dash-dots) and F127/melamine/SHMP coating itself without cotton fabric (green dashes). Each curve represents the average of 3 replicates.

Figure 5. SEM images (a) cotton control (b) $15 \%$ F127/15 \% melamine/15 \% SHMP on cotton fabric (c) $5 \%$ melamine/5\% SHMP on cotton fabric. The $5 \%$ melamine $/ 5 \%$ SHMP coating is not very uniform on the cotton fibers and is randomly dispersed. The $15 \%$ F127/15 \% melamine/15 \% SHMP coating shows a more uniform back-coating on the cotton fibers but there are noticeable cracks which indicates insufficient adhesion of the coating onto the cotton fabric

Figure 6. Comparison of MCC data for F127, melamine, and SHMP coatings to the previously reported single bath, LbL, and MDPA/TMM coatings on or deposits within cotton fabrics. Mass gain \% (blue), residue \% (orange), THR (kJ/g) \% reduction (grey), and PHRR (W/g) \% reduction (yellow) for each formulation is compared. Data is reported with a $2 \sigma$ standard uncertainty .....12 


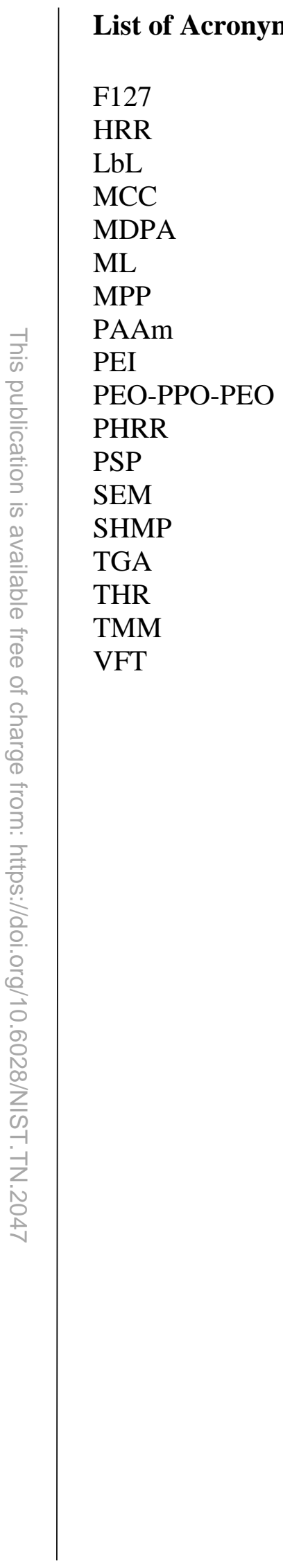




\section{Introduction}

Fire is a useful tool throughout human history, but it can bring disasters if not carefully controlled ${ }^{[1]}$. By inhibiting a voluminous fire, there is a better chance for fire-fighters to extinguish it or for people to escape uncontrolled fires before they cause significant damage. Cotton is a very important natural textile fiber used to produce clothing, furniture, and industrial products, but it has a low limiting oxygen index $(18 \%)^{[2]}$ and thermal decomposition temperature $\left(360^{\circ} \mathrm{C}\right.$ to $\left.425^{\circ} \mathrm{C}\right)$ that makes it very flammable ${ }^{[3]}$. When cotton fabrics are ignited, the flames spread rapidly potentially causing fatal burns within $15 \mathrm{~s}$ of ignition ${ }^{[4]}$. Various methods are used to impart flame retardancy to cotton fabrics ${ }^{[5-10]}$. Halogenated and boron containing additives are widely used that function by liberating large volumes of non-flammable gases to starve the flames and forming a glass coating, respectively, during thermal decomposition ${ }^{[4,11]}$. Boron-based flame retardants are quite water soluble and might impart only momentary flame retardancy on fabrics that undergo numerous washing cycles ${ }^{[3,12]}$. The effectiveness of commonly used halogenated flame retardants are compromised by their latent toxicity concerns linked with bioaccumulation and exposure issues to both humans and aquatic species in the environment ${ }^{[13]}$. While there are certainly new halogenated chemistries that might prove somehow better than those compounds with documented concerns, our focus in this manuscript is the use of phosphorus-based flame retardants, which are used to impart flame retardancy to cellulosic fabrics ${ }^{[14,15]}$. Some Phosphorous-based coatings can withstand repeated wash cycles ${ }^{[3,12]}$, reduce volatile fuel, lower pyrolysis temperature, increase carbonaceous char, and decrease afterglow ${ }^{[14]}$. Leistner et al. studied the use of chitosan/melamine polyphosphate as a water-insoluble coating on cotton fabric via layer-by-layer assembly ${ }^{[15]}$.

Layer-by-layer (LbL) deposition ${ }^{[16-20]}$ is a common technique for fabricating thinner, multifunctional flame retardant films/coatings. These coatings are formed by repeatedly depositing alternating layers of oppositely charged materials. The multilayer assembly of the coating is self-regulated by electrostatic repulsion within the individual layers and is enabled by attractive forces; electrostatic ${ }^{[21]}$, van der Waals ${ }^{[22,23]}$, and Hydrogen bonding ${ }^{[24,25]}$. LbL coatings/films can be applied by either dip coating ${ }^{[26,27]}$ or spray coating ${ }^{[28,29]}$. They have range of functionalities that can produce conducting films ${ }^{[30-32]}$, antireflection films ${ }^{[33,34]}$, and oxygen barriers ${ }^{[35,36]}$. The downside of $\mathrm{LbL}$ is each additional monolayer (ML) requires an additional deposition and washing step; therefore, 20 or more monolayer coatings required a total of 30 or more steps in the fabrication process, More recently, researchers have pivoted from layer-bylayer assembly and are aiming for single bath processes for fabricating a flame retardant coating on fabrics ${ }^{[37]}$ and polyurethane foams ${ }^{[38]}$ because it can be faster, use less materials, and generate less waste. In this manuscript, we are reporting on a reduced flammability coat fabric as result of using a water-insoluble, flame resistant gel coating constructed from melamine, sodium hexametaphosphate (SHMP), and polyethylene oxide-polypropylene oxide-polyethylene oxide, PEO-PPO-PEO, triblock copolymer.

SHMP ${ }^{[39]}$, melamine ${ }^{[40]}$, and PEO-PPO-PEO triblock copolymers are, in small doses, non-toxic chemicals. SHMP is used as a sequestrant and as a food additive ${ }^{[41]}$. Melamine is the 
starting material for resins used in the production of a wide variety of thermosetting plastics ${ }^{[42]}$. When melamine is mixed with SHMP in aqueous solutions, they form the water-insoluble melamine polyphosphate (MPP), a well-known fire retardant ${ }^{[15]}$. The amphiphilic PEO-PPOPEO triblock copolymer Pluronic F127 ${ }^{1}$ has surfactant properties that make it useful in industrial applications such as, drug delivery ${ }^{[43,44]}$. Here, our goal is to move away from LbL coatings and use the gelation properties of F127 with melamine and SHMP to form a flame resistant coating on cotton fabrics.

Researchers have attributed the mechanism of gel formation for the aqueous dispersions of PEO-PPO-PEO triblock copolymers to the close packing and ordering of micelles ${ }^{[45-47]}$. The PEO-PPO-PEO triblock copolymer F127 (70 \% PEO content) has the most pronounced gel forming abilities of the commercially available polymer surfactants ${ }^{[48]}$. As the temperature of these solutions is increased, the decreasing aqueous solubility of the PPO causes micelle formation with the hydrophobic (PPO) cores and hydrophilic (PEO) shells ${ }^{\text {[49] }}$. Lam et al ${ }^{\text {[50] }}$ suggested that the micelles grow via Ostwald ripening, and Barba et al ${ }^{[51]}$ suggested that the volume fraction occupied by the micelles in solution rises with increasing temperature. The micelles experience repulsive interactions and order into quasicrystalline cubic lattices ${ }^{[49]}$. The observed lattice structure for F127 gels are typically face centered cubic or body centered cubic [52, 53]. F127's lattice structure is believed to give micelle materials their gel-like properties ${ }^{[49]}$.

This manuscript describes chemical formulations and single bath procedures to yield nontoxic, flame resistant coatings for cotton fabrics. The coatings were made with the amphiphilic PEO-PPO-PEO triblock copolymer F127, melamine, and SHMP. The impact of the formulations on flammability was determined by measuring flame resistance, heat released rate, and thermal decomposition behavior using vertical flame testing (VFT), micro-scale combustion calorimetry (MCC), and thermogravimetric analysis (TGA) respectively. Scanning electron microscopy (SEM) was used to observe surface quality assessments of the coatings on the cotton fabrics.

\section{Experimental Materials and Test Methods}

\subsection{Materials}

Unless otherwise indicated, all materials were used as received, all percentage values are mass fraction percent, and all data is reported with a $2 \sigma$ standard uncertainty. Polyethylene oxide-polypropylene oxide-polyethylene oxide, PEO-PPO-PEO Pluronic F127 (12,600 g/mol molecular mass), SHMP ( $\mathrm{Na}_{6} \mathrm{P}_{6} \mathrm{O}_{18}, 611.77 \mathrm{~g} / \mathrm{mol}$ molecular mass), and melamine $\left(\mathrm{C}_{3} \mathrm{H}_{6} \mathrm{~N}_{6}\right.$, $126.12 \mathrm{~g} / \mathrm{mol}$ molecular mass) were obtained from Sigma-Aldrich (Milwaukee, WI) and were used as received. The structures of each are shown in Figure 1. The cotton fabric (James Thompson \& Co. Inc., 228.6 cm Quilter’s Flannel, double-napped 100 \% cotton, area density of $102 \mathrm{~g} / \mathrm{m}^{2}$ ) was used as received. All solutions were prepared using deionized water from a PURELAB Flex $(18.2 \mathrm{M} \Omega \cdot \mathrm{cm}$, ELGA).

${ }^{1}$ Certain commercial equipment, instruments, or materials are identified in this paper in order to specify the experimental procedure adequately. Such identification is not intended to imply recommendation or endorsement by the National Institute of Standards and Technology, nor is it intended to imply that the materials or equipment identified are necessarily the best available for this purpose. 


$$
\begin{aligned}
\left.\left.\mathrm{H}+\mathrm{OCH}_{2} \mathrm{CH}_{2}\right)_{\mathrm{F}} \mathrm{OCHCH}_{2}\right)_{y} \mathrm{CH}_{3}\left(\mathrm{OCH}_{2} \mathrm{CH}_{2}\right)_{\mathrm{n}} \mathrm{OH} \\
\mathrm{F} 100, y=65)
\end{aligned}
$$

(a)<smiles>[NH3+]O[PH3+]</smiles>

(c)

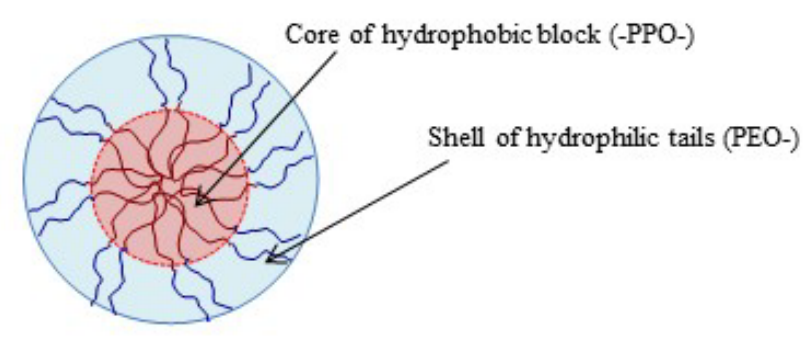

(b)

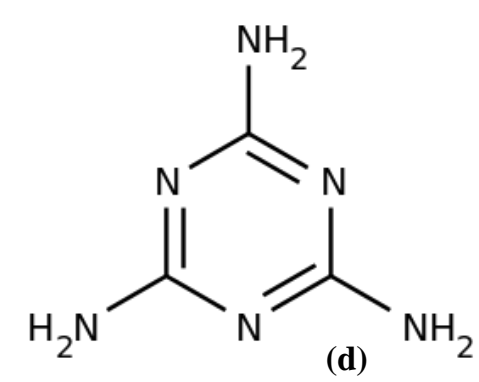

Figure 1. (a) F127 (b) Schematic of PEO-PPO-PEO micelle structure (c) Sodium hexametaphosphate (d) Melamine.

\subsection{Coating Procedure}

Aqueous solutions of F127 were prepared according to “cold” processing methods ${ }^{\text {[48] }}$ and formulated in varying concentrations (10\% to $20 \%$ ) to probe its flame retarding properties. Concentrations of melamine (5\% to $15 \%$ ) were mixed in aqueous solutions of F127. Lastly, SHMP (5 \% to $15 \%$ ) was added at varying concentrations. The total volume of the mixtures during treatment was held constant as an attempt to control the thickness of the coatings. After several hours of mixing at room temperature, the coating gel formed. The white gel was coated onto the backside of the cotton fabric $(10 \mathrm{~cm} \times 10 \mathrm{~cm})$ using a stainless-steel laboratory spatula. The coated cotton fabric was placed in an oven for at least $12 \mathrm{~h}$ at $70^{\circ} \mathrm{C}$. When the fabric still felt damp to the touch after $12 \mathrm{~h}$, it was placed back in the oven at $70{ }^{\circ} \mathrm{C}$ until moisture was no longer present. Two types of coating protocols were followed. One was for melamine, SHMP, and F127. The other was for just melamine and SHMP (no F127). The protocol without F127 used aqueous solutions of melamine (5 \%) and SHMP (5\%) all mixed into a single bath. The cotton fabric was manually dipped into the solution and soaked for $10 \mathrm{~min}$ to allow complete wetting and good adhesion of the coating to the substrate. The coated cotton fabric was then placed in an oven at $70^{\circ} \mathrm{C}$ for a minimum of $12 \mathrm{~h}$. The resulting color of the cotton fabric turned white due to the melamine polyphosphate. Post coating, the overall feel of the fabric felt stiffer and heavier. 


\subsection{Flammability Testing}

Vertical flame testing (VFT) was used as a screening process to identify potential flame resistant coating formulations (3 replicates each). The potential formulations were reproduced, and their combustion behavior was measured using micro-scale combustion calorimetry (MCC). MCC tests were conducted from $100^{\circ} \mathrm{C}$ to $750{ }^{\circ} \mathrm{C}$ under an environment of $20 \%$ oxygen and 80 $\%$ nitrogen with a heating rate of $1^{\circ} \mathrm{C} / \mathrm{s}$ and a sample mass of 5mg; using a ASTM D7309 compliant test apparatus (Concept Equipment). MCC tests revealed the influence of the coating on the fabric's heat release. Thermogravimetric analysis (TGA) was performed to understand the mass loss of the coated sample due to non-oxidative thermal decomposition. TGA tests were conducted from $90{ }^{\circ} \mathrm{C}$ to $850{ }^{\circ} \mathrm{C}$ under nitrogen with a constant heating rate of $20^{\circ} \mathrm{C} / \mathrm{min}$ and a sample mass of $10 \mathrm{mg}$, using a NETZSCH STA 449 F1 instrument (Germany).

No conditioning was performed prior to testing. The vertical flame test was setup as shown in Figure 2. The VFT used was for screening purposes only and does not follow NFPA 701: Standard Methods of Fire Tests for Flame Propagation of Textiles and Films protocol. The ignition process was to apply a butane micro torch $\left(\approx 1430{ }^{\circ} \mathrm{C}\right)$ to the middle, bottom edge of the sample $(10 \mathrm{~cm} \times 10 \mathrm{~cm})$ for $5 \mathrm{~s}$. If the sample failed to ignite or it self-extinguished, the torch was applied again at the same place on the fabric for another $5 \mathrm{~s}$. This ignition process was repeated no more than three times on the same specimen. The test was complete when no flames were visible or when the specimen was completely consumed during combustion. The $100 \%$ cotton fabric was used as a control to qualitatively rank the formulations. Ignitibility and flame spread was characterized based on the following: number of applications of the torch before ignition, time until flames extinguished, and extent of flame propagation upwards and across the cotton surface. The results of these tests are shown in Table 1.

\subsection{Morphological Characterization}

A Ziess Ultra 60 Field Emission-Scanning Electron Microscope (FE-SEM, Carl Zeiss

Inc., Thornwood, NY) was used to acquire surface images of the coatings on the cotton fabrics under a $5 \mathrm{kV}$ accelerating voltage. All SEM samples were sputter-coated with $8 \mathrm{~nm}$ of gold/platinum (60 \% / $40 \%$ by mass) prior to imaging. 


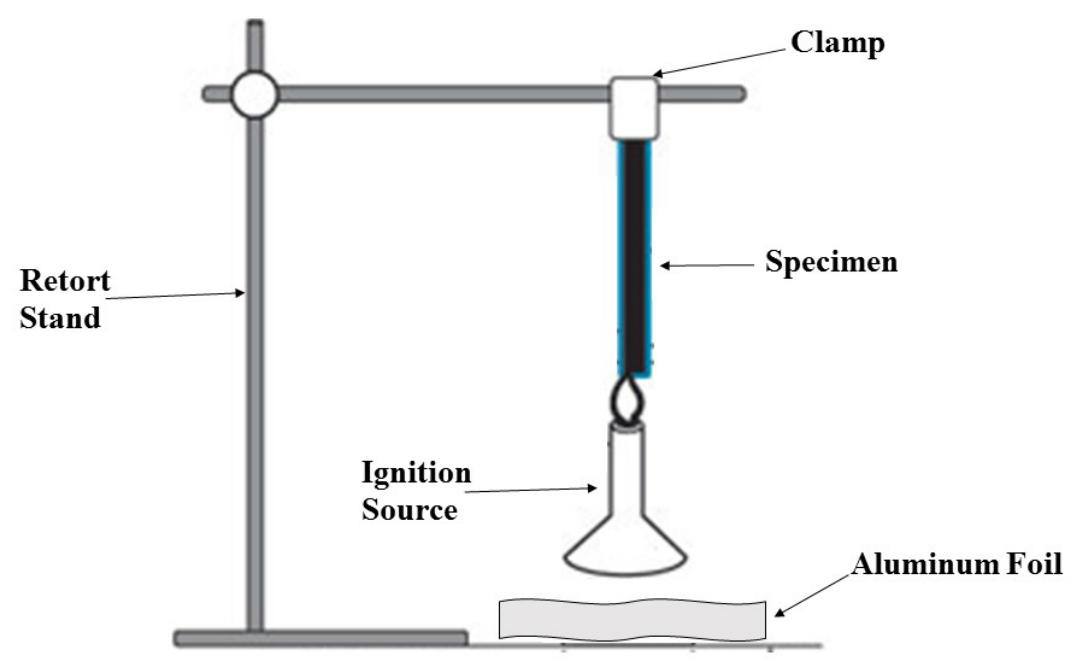

Figure 2. Schematic of vertical flame test (VFT) setup. Note: Drawing not to scale.

\section{Results and Discussion}

In a single step coating process, PEO-PPO-PEO (F127), co-formulated with melamine and sodium hexametaphosphate (SHMP) were deposited as gel coatings on cotton fabrics. The gel coatings were characterized to determine coating morphology (SEM) and flame resistance (vertical flame testing). Only the coatings that did not ignite were evaluated using MCC, TGA, and SEM.

\subsection{Fabrication and Flammability Screening}

Nine flame resistant-coated cotton fabric combinations were produced by applying gel coating solutions containing F127 (0 \%, $15 \%$, and $20 \%$ ), melamine (0 \%, 5 \%, $10 \%$, and 15 $\%)$, and SHMP (0 \%, $5 \%, 10 \%, 15 \%)$. The cotton control, coating compositions, mass gain percent (percentage of mass increase after coating is applied), and flammability results are provided below in Table 1. The data in Table 1 reflects the averages of at least three specimens for each formulation.

Flammability of a material is defined by a number of factors, including its flame resistance and the rate of heat generated by fire. When screening various formulations of coatings on fabrics, flame resistance was prioritized. Therefore, in this study, flame resistance tests were used as initial screens of fabric flammability.

Based on the flame test (Table 1), all the formulations increased the flame resistance of cotton. The control and $20 \%$ F127 gel coated cotton fabrics ignited as soon as the flame was applied. Within $60 \mathrm{~s}$ the fabrics were completely engulfed in flames. The best performing coatings (no ignition, Table 1) were the 5 \% melamine/5 \% SHMP, 20 \% F127/15 \% melamine/15 \% SHMP, and 15 \% F127/15 \% melamine/15 \% SHMP formulations. Depending on the coating formulation, the overall mass gain of cotton fabric is dramatically affected. Therefore, the $20 \%$ F127/15 \% melamine/15 \% SHMP coating on cotton was no longer explored as the $15 \%$ F127/15 \% melamine/15 \% SHMP coating on cotton produced a lower mass gain 
with no ignition. The lower overall mass gain also attributed to a more flexible and softer fabric compared to the higher mass gains. Based on these observations, we attempted to produce a 10 \% F127/15 \% melamine/15 \% SHMP coating. However, a coating gel did not form because the concentration of F127 was well below the critical gel formation concentration (typically $\approx 20 \%$ mass fraction ${ }^{[48]}$ ). In this case, adding melamine and SHMP was not a strong enough driving force to form a gel at $10 \%$ F127. In order to compare the combustion behavior and thermal decomposition of the coating itself before applying it onto cotton fabrics to the coated fabrics, a 20 \% F127/15 \% melamine/15 \% SHMP coating was also analyzed using MCC and TGA.

Table 1. Coating composition, mass gain percent (\%), and open flame screening for flame retardant-coated cotton fabrics. Mass gain is reported with a $2 \sigma$ standard uncertainty.

\begin{tabular}{ccccl}
\hline \multicolumn{2}{c}{ Coating Composition (\%) } & Mass Gain (\%) & \multirow{2}{*}{ Flammability Observations } \\
\hline 25 & Melamine & SHMP & Ignition, slow flame spread \\
20 & 10 & 10 & $143 \pm 10$ & No ignition \\
20 & 15 & 15 & $238 \pm 10$ & Ignition, slow flame spread \\
20 & 15 & - & $143 \pm 10$ & Ignition, charred \\
20 & - & 15 & $137 \pm 10$ & Complete combustion \\
15 & - & - & $105 \pm 10$ & No ignition \\
- & 15 & 15 & $220 \pm 10$ & No ignition \\
- & 5 & 5 & $54 \pm 10$ & Extensive combustion \\
- & 5 & - & $30 \pm 10$ & Ignition, charred \\
- & - & 5 & $10 \pm 10$ & Complete combustion \\
\hline
\end{tabular}

\subsection{Thermal Analysis}

As shown in Figure 3 and Table 2, TGA results on untreated cotton show mass loss below $225{ }^{\circ} \mathrm{C}$ and a rapid decline in residual mass with rising temperature above $225{ }^{\circ} \mathrm{C}$. The lower and higher temperature decompositions can be interpreted as a two-stage decomposition process with slopes of percent mass loss $/{ }^{\circ} \mathrm{C}$ summarized in Table 2 . The slopes were calculated using $\mathrm{m}=\left(\mathrm{y}_{2}-\mathrm{y}_{1}\right) /\left(\mathrm{x}_{2}-\mathrm{x}_{1}\right)$. Coating cotton with the SHMP/melamine mixtures led to TGA results that show some intermediate plateau of mass stability with increasing temperature (see Table 2). The mass loss at lower temperatures for the coated fabrics is due to the thermal decomposition of melamine and SHMP. Both the coating and the cotton contribute to the mass loss of the coated fabrics. Despite the 15 \% F127/15 \% melamine/15 \% SHMP coating losing mass at lower temperatures than the cotton control, the mass above $400{ }^{\circ} \mathrm{C}$ for cotton is less than $5 \%$ while that for the coated cotton is about $15 \%$ or less.

The $5 \%$ melamine/5 \% SHMP, 15 \% F127/15 \% melamine/15 \% SHMP coated cotton, and the $20 \%$ F127/15 \% melamine/15 \% SHMP coating exhibited similar TGA profiles, except the coatings had higher mass residues at the end of the test compared to cotton. For cotton 
control fabric, thermal decomposition ended at $\approx 375{ }^{\circ} \mathrm{C}$ with $5 \% \pm 1 \%$ of the original mass as char residue.

Significant mass changes in the TGA residue occurred when the cotton fabric was coated with $15 \%$ F127/15 \% melamine/15 \% SHMP and 5 \% melamine/5 \% SHMP. The onset degradation temperature occurred at $150{ }^{\circ} \mathrm{C}$ and $185^{\circ} \mathrm{C}$ for $15 \% \mathrm{~F} 127 / 15 \%$ melamine/15 \% SHMP and $5 \%$ melamine $/ 5 \%$ SHMP, respectively. For comparison, this was observed at $75{ }^{\circ} \mathrm{C}$ for the cotton control. In addition, the char yield increased from $5 \% \pm 1 \%$ for cotton control at $375{ }^{\circ} \mathrm{C}$ to $10 \% \pm 2 \%$ ( $\approx 100 \%$ increase) at $450{ }^{\circ} \mathrm{C}$ for $15 \%$ F127/15 \% melamine/15 \% SHMP coating. The percent mass loss for $20 \%$ F127/15 \% melamine/15 \% SHMP coating is lower than the percent mass loss for cotton control, which suggests the coating is more thermally stable than cotton. The 15 \% F127/15 \% melamine/15 \% SHMP coating on cotton fabric has a lower percent mass loss than the cotton control, which suggests this coating on cotton lowers the thermal decomposition behavior. The mass loss behavior for $15 \%$ F127/15 \% melamine/15 \% SHMP is similar to that for flame retardant agent CFR-201 (an organophosphorus nitrogen containing compound) reported by Zhu et al ${ }^{[54]}$. Zhu et al ${ }^{[54]}$ also divided the pyrolysis process of cellulose fiber into an initial pyrolysis stage, main pyrolysis stage, and char pyrolysis stage with temperature ranges of $80^{\circ} \mathrm{C}$ to $300{ }^{\circ} \mathrm{C}, 300{ }^{\circ} \mathrm{C}$ to $400{ }^{\circ} \mathrm{C}$, and $400{ }^{\circ} \mathrm{C}$ respectively. Their flame retardant fibers also decomposed at lower corresponding temperatures but formed higher residue than that of the untreated cotton.

MCC was used to study the combustion behavior of the same formulations analyzed by TGA. Figure 4 shows the heat release rate (HRR) of coated and uncoated cotton with temperature $\left({ }^{\circ} \mathrm{C}\right)$. Heat release properties from MCC analysis are shown in Table 3.

As shown in Figure 4 and Table 3, relative to the cotton control, $5 \%$ melamine $/ 5 \%$ SHMP and 15 \% F127/15 \% melamine/15 \% SHMP both show lower heat release rates, THR, PHRR, and higher residue mass values. For cotton, thermal decomposition began at approximately $300{ }^{\circ} \mathrm{C}$. The thermal decomposition, as indicated by rising HRR, intensified as the temperature rose. The average maximum $\mathrm{HRR}$ at $400{ }^{\circ} \mathrm{C}$ was $178 \mathrm{~W} / \mathrm{g} \pm 7 \mathrm{~W} / \mathrm{g}$, which was identified as the peak heat release rate (PHRR). The thermal decomposition was complete at 550 ${ }^{\circ} \mathrm{C}$ with an average of $12 \% \pm 1 \%$ of the original mass as char residue.

As a percentage basis, the reduction in PHRR is more significant by coating (reductions as much as $2 / 3$ of PHRR cotton) whereas the total heat release was only $\approx 16 \%$ lower on average overall with the same coating conditions. The released energy measurements compare

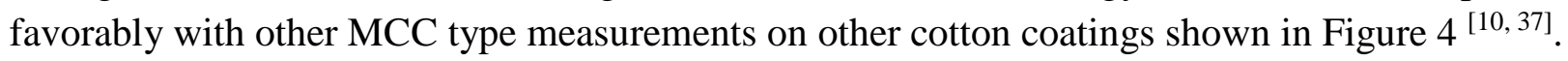

As shown in Figure 4, the HRR curve for cotton control has one peak and F127 coatedcotton fabrics have 3 peaks. The first peak of cotton's thermal decomposition (temperature range $300^{\circ} \mathrm{C}$ to $325^{\circ} \mathrm{C}$ ) is due to the thermal decomposition of melamine and SHMP (see Figure 4a). The second peak (temperature range $325^{\circ} \mathrm{C}$ to $425^{\circ} \mathrm{C}$ ) is due to the decomposition of the cotton fabric. The third peak (temperature range $400^{\circ} \mathrm{C}$ to $450^{\circ} \mathrm{C}$ ) is due to the decomposition of the F127 gel (see Figure 4c) which contains no cotton fabric and displays a peak in the same temperature range. Early thermal decomposition of a flame retardant could reduce its 
effectiveness on the coated cotton fabric. Therefore, identifying even more effective flame retardants packaged within a gel deserves to be probed more. SEM images observed the coating quality (surface morphology) of the coated samples. SEM images for $15 \%$ F127/15 \% melamine/15 \% SHMP, $5 \%$ melamine/5 \% SHMP, and cotton control are provided in Figure 5.

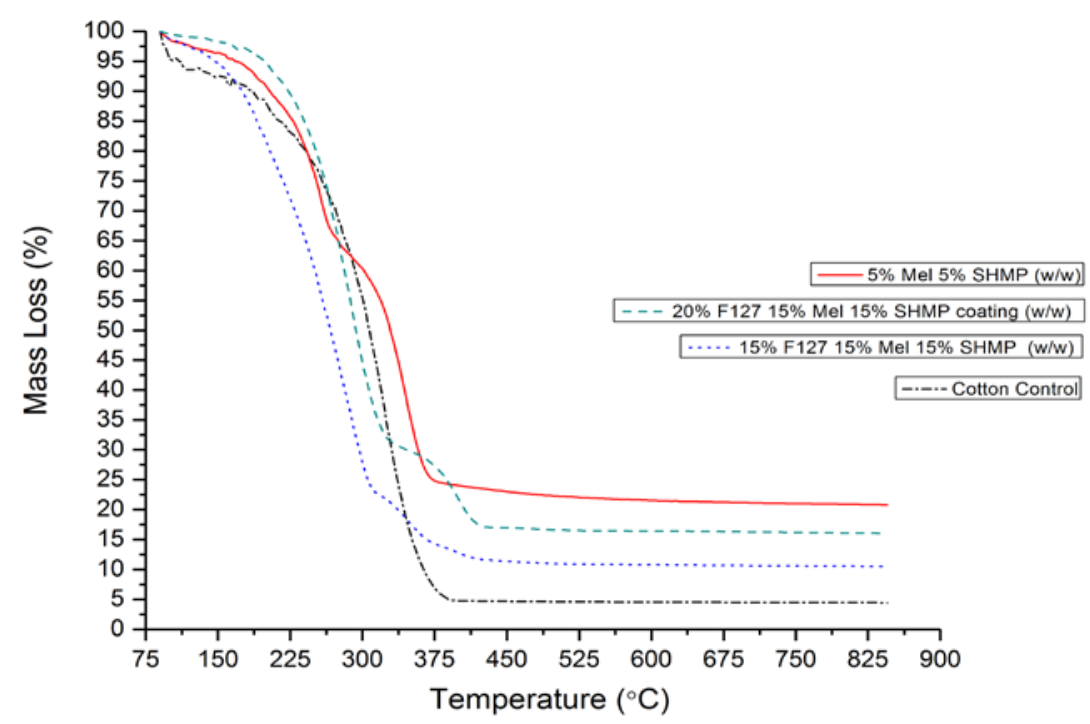

Figure 3. TGA data for F127/melamine/SHMP gel coating on cotton fabric (blue dots), melamine/SHMP (red solid line), uncoated cotton fabric (black dash-dots), and coating itself without cotton fabric (green dashes).

Table 2. TGA properties of uncoated cotton fabric, melamine/SHMP on cotton, F127/melamine/SHMP gel coating on cotton, and F127/melamine/SHMP coating itself. Data is reported with a $2 \sigma$ standard uncertainty. The slopes correspond to the dehydration of the coated fabric (1) followed by the active combustion of the dehydrated composite (2).

\begin{tabular}{|c|c|c|c|c|}
\hline Sample ID & $\begin{array}{c}\text { 1 }^{\text {st }} \text { Slope } \\
\left(\% /{ }^{\circ} \mathrm{C}\right)\left(\mathrm{R}^{2}\right)\end{array}$ & $\begin{array}{c}2^{\text {nd }} \text { Slope } \\
\left(\% /{ }^{\circ} \mathrm{C}\right)\left(\mathrm{R}^{2}\right)\end{array}$ & $\begin{array}{c}\text { Intermediate Plateau } \\
\text { Temperature Range }\left({ }^{\circ} \mathrm{C}\right)\end{array}$ & $\begin{array}{c}\text { Residue } \\
(\%)\end{array}$ \\
\hline Cotton Control & $\begin{array}{l}-0.07 \\
(0.86)\end{array}$ & $\begin{array}{c}-0.5 \\
(0.95)\end{array}$ & - & $5 \pm 1$ \\
\hline $\begin{array}{c}5 \% \text { Melamine } \\
5 \% \text { SHMP }\end{array}$ & $\begin{array}{l}-0.05 \\
(0.97)\end{array}$ & $\begin{array}{c}-0.3 \\
(0.94)\end{array}$ & 275 to 375 & $20 \pm 2$ \\
\hline $\begin{array}{c}15 \% \text { F127 } \\
15 \% \text { Melamine } \\
15 \% \text { SHMP }\end{array}$ & $\begin{array}{l}-0.08 \\
(0.99)\end{array}$ & $\begin{array}{c}-0.5 \\
(0.97)\end{array}$ & 300 to 375 & $10 \pm 2$ \\
\hline $\begin{array}{c}20 \text { \% F127 } \\
15 \% \text { Melamine } \\
15 \% \text { SHMP coating }\end{array}$ & $\begin{array}{l}-0.04 \\
(0.93)\end{array}$ & $\begin{array}{l}-0.6 \\
(0.97)\end{array}$ & 325 to 425 & $15 \pm 2$ \\
\hline
\end{tabular}




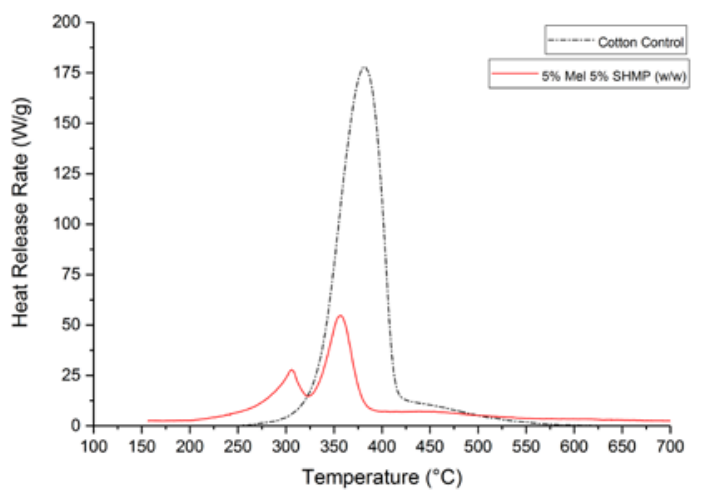

(a)

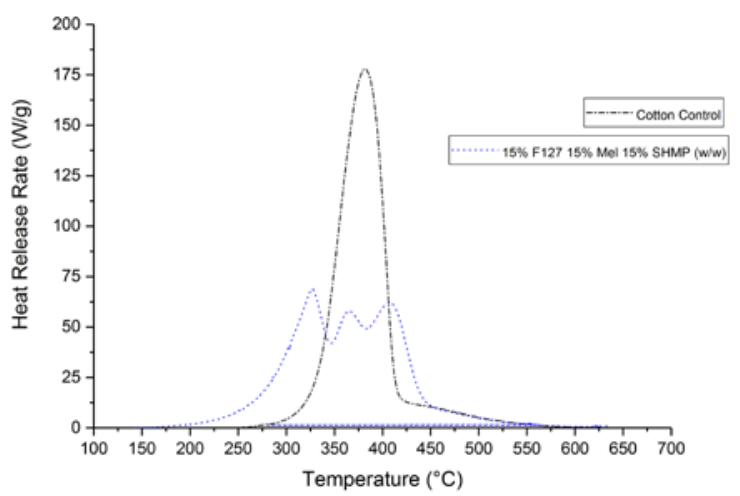

(b)

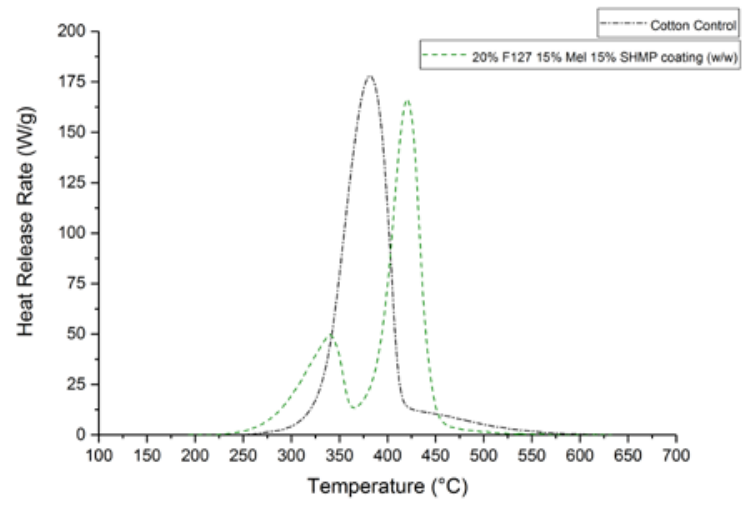

(c)

Figure 4. MCC results of (a) uncoated cotton fabric (black dash-dots) and melamine/SHMP (red solid line) (b) uncoated cotton fabric (black dash-dots) and F127/melamine/SHMP gel coating on cotton fabric (blue dots) (c) uncoated cotton fabric (black dash-dots) and F127/melamine/SHMP coating itself without cotton fabric (green dashes). Each curve represents the average of 3 replicates. 
Table 3. Heat release properties of uncoated cotton fabric, melamine/SHMP on cotton, F127/melamine/SHMP gel coating on cotton, and F127/melamine/SHMP coating itself. Data represents the average of 3 replicates and is reported with a $2 \sigma$ standard uncertainty.

\begin{tabular}{cccc}
\hline Sample ID & $\begin{array}{c}\text { Residue (\%) } \\
\text { (\% increased) }\end{array}$ & $\begin{array}{c}\text { THR (kJ/g) } \\
\text { (\% reduction) }\end{array}$ & $\begin{array}{c}\text { PHRR (W/g) } \\
\text { (\% reduction) }\end{array}$ \\
\hline Cotton Control & $12 \pm 1$ & $11 \pm 0.1$ & $178 \pm 7$ \\
5 \% Melamine & $44 \pm 5$ & $4 \pm 1$ & $55 \pm 14$ \\
$5 \%$ SHMP & $(267 \pm 5)$ & $(68 \pm 1)$ & $(69 \pm 14)$ \\
15\% F127 & $25 \pm 6$ & $9 \pm 1$ & $69 \pm 5$ \\
$15 \%$ Melamine & $(108 \pm 6)$ & $(16 \pm 1)$ & $(61 \pm 5)$ \\
$15 \%$ SHMP & & & $166 \pm 45$ \\
20 \% F127 & $19 \pm 7$ & $9 \pm 2$ & \\
$15 \%$ Melamine & & & \\
$15 \%$ SHMP coating & & & \\
\hline
\end{tabular}
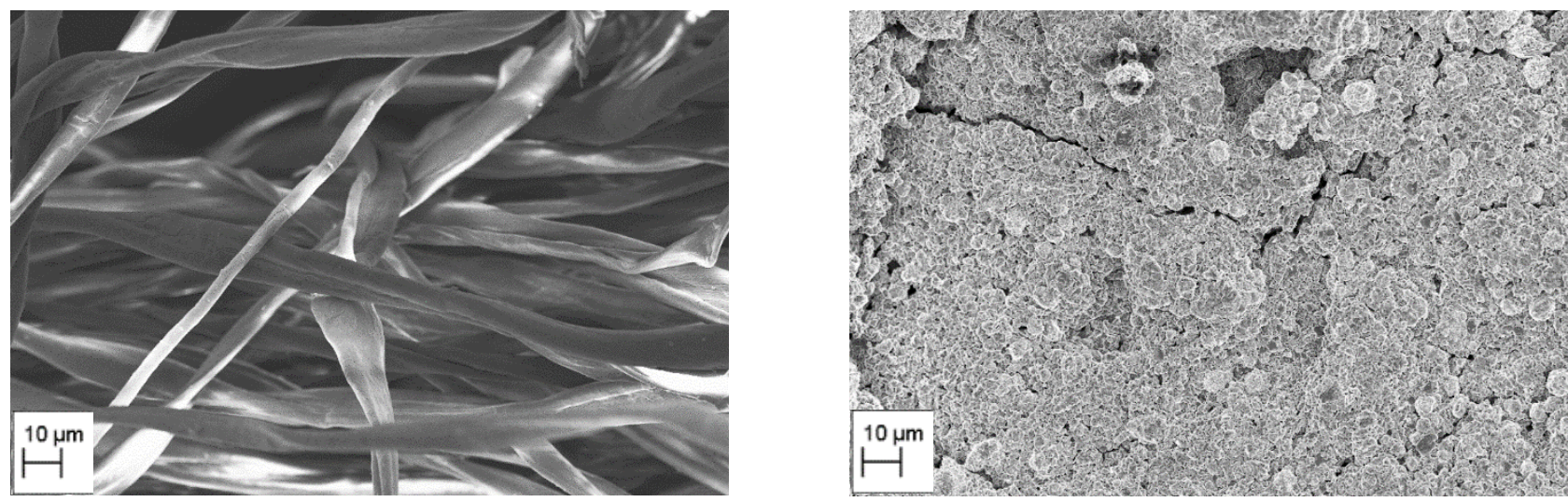

(a)

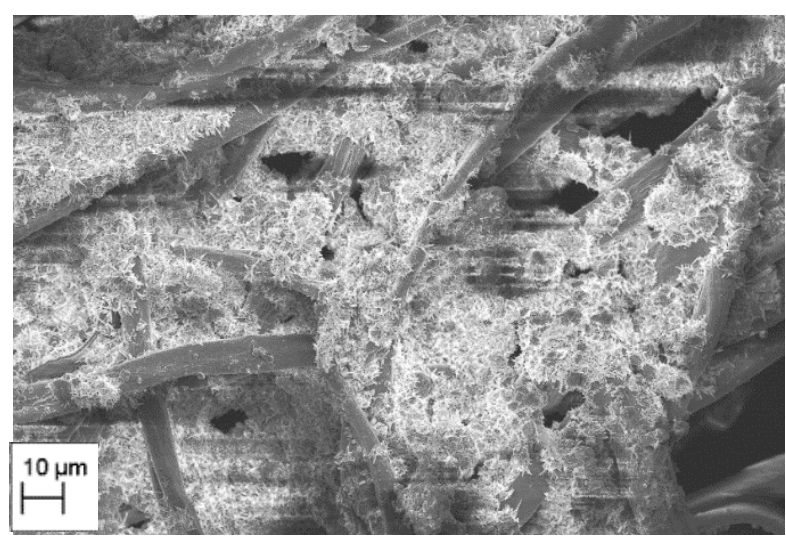

(b)

(c)

Figure 5. SEM images (a) cotton control (b) $15 \%$ F127/15 \% melamine/15 \% SHMP on cotton fabric (c) $5 \%$ melamine/5 \% SHMP on cotton fabric. The $5 \%$ melamine/5 \% SHMP coating is not very uniform on the cotton fibers and is randomly dispersed. The $15 \%$ F127/15 \% melamine/15 \% SHMP coating shows a more uniform back-coating on the cotton fibers but there are noticeable cracks which indicates insufficient adhesion of the coating onto the cotton fabric. 
Some coating was observed on the $5 \%$ melamine/5 \% SHMP, but the coating is randomly dispersed as some fibers have more coating on them than others. For the $15 \%$ F127/15 $\%$ melamine/15 \% SHMP coating on cotton fabric, it shows a more uniform mixture of backcoating on the cotton fibers with all of the fibers coated. There are some noticeable cracks that appear in the image which indicates insufficient adhesion of the back-coating on the cotton fabric. A more uniform and thinner back-coating is required to ensure the flame does not touch the fabric directly without dramatically adding to the cotton mass. The back-coating acts as a protective layer for the fabric so the flame will contact the coating first, causing no ignition of the fabric. This was a proof in concept and more work is needed to explore a more uniform backcoating thickness.

\subsection{Comparison to other technologies}

Previously reported flame retardant strategies, incorporated in or applied onto cotton fabrics ${ }^{[10,15,37]}$ are shown in Figure 6 . These flame retardants were deposited using single bath and LbL assembly protocols and constructed using N-methylol dimethylphosphonopropionamide (MDPA) and trimethylol melamine (TMM) ${ }^{[10]}$, soaked in a polyethylenimine (PEI)/poly(phosphate sodium salt) (PSP) complex ${ }^{\text {[37] }}$, polyallylamine/poly(phosphate sodium salt) (PAAm/PSP) ${ }^{[37]}$, and $\mathrm{PA} / \mathrm{CH}$ at $\mathrm{PH} 4{ }^{[37]}$. The LbL coatings ranged from 10 monolayers (ML) to 64 monolayers and resulted in a mass increase of $2 \%$ to $18 \%$. These deposited coatings yielded heat release reductions of $42 \%$ to $61 \%$ (PHRR) and $54 \%$ to $76 \%$ (THR).

All coatings reduce the cotton flammability as assessed by MCC. In terms of total energy of combustion, the gel-coating has lower energy released relative to any of the other coatings. That improvement comes at the cost of a huge increase in coating thickness, primarily consisting of amphiphilic copolymer. The amphiphile is still hydrophilic even after the drying process. The low THR can be attributed to the gel absorbing energy during the combustion process. Of course, if the coating thickness could be optimized to not triple the mass of the fabric, the effectiveness of the coating might be diminished. The coating thickness could also be affected if the amphiphiles were extracted from the gel coating with subsequent washings. In terms of a peak combustion rate, there is little difference between the formulations except the MDPA/TMM coating which statistically produced the lowest PHRR. It is also interesting to note that the presence of more LbL layers adds to the mass but does not improve the residue or the energy of combustion, which suggests the thinnest LbL coatings are more efficient in enhancing flame retardancy. 


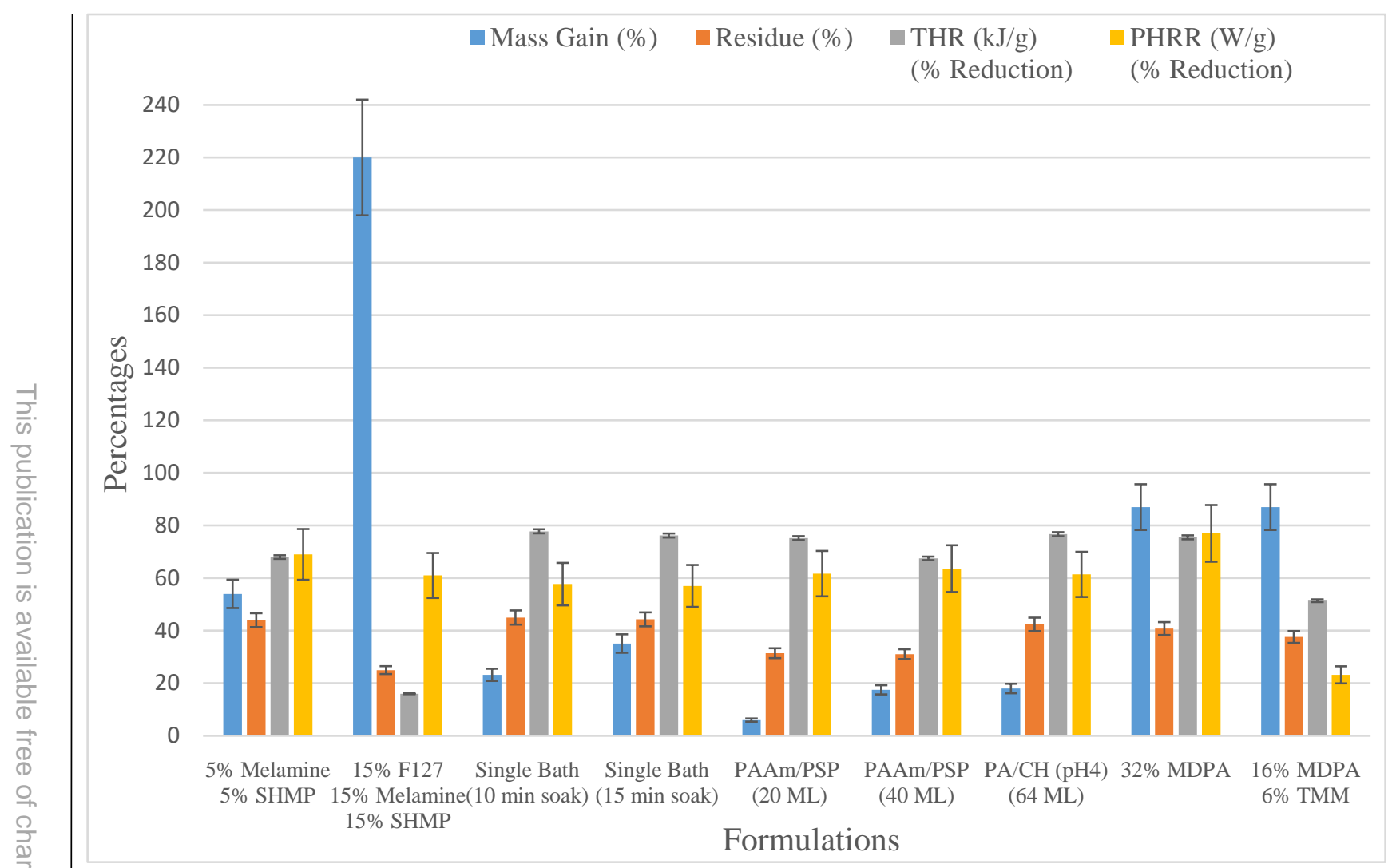

Figure 6. Comparison of MCC data for F127, melamine, and SHMP coatings to the previously reported single bath ${ }^{[37]}$, LbL ${ }^{[37]}$, and MDPA/TMM ${ }^{[10]}$ coatings on or deposits within cotton fabrics. Mass gain \% (blue), residue \% (orange), THR (kJ/g) \% reduction (grey), and PHRR (W/g) \% reduction (yellow) for each formulation is compared. Data is reported with a $2 \sigma$ standard uncertainty.

\subsection{Experimental Uncertainty}

There are different components of uncertainty in the mass, char yield, temperature, HRR, THR, and PHRR reported here. Uncertainties are grouped into two categories according to the method used to estimate them. Type A uncertainties are those which are evaluated by statistical methods, and Type B are those which are evaluated by other means [55]. Type B analysis of systematic uncertainties involves estimating the upper $(+a)$ and lower $(-a)$ limits for the quantity in question such that the probability that the value would be in the interval $( \pm$ a) is essentially $100 \%$. After estimating uncertainties by either Type A or B analysis, the uncertainties are combined in quadrature to yield the combined standard uncertainty. Multiplying the combined standard uncertainty by a coverage factor of two results in the expanded uncertainty which corresponds to a $95 \%$ confidence interval $(2 \sigma)$.

Components of uncertainty are tabulated in Table 4. Some of these components, such as the balance drift, temperature, and heat release measurements are derived from instrument 
specifications. Other components, such as coating composition include past experience with coatings.

The best single predictor of the fire hazard of a material is its heat release rate in flaming combustion. However, heat release rate is difficult to quantify because is depends on fire size (heating rate), sample thickness, and the amount of oxygen available for combustion. The MCC and TGA instruments eliminate this uncertainty by using controlled heating and excess oxygen to measure a specific heat release rate (watts per gram) that depends only on the material being tested and the heating rate. Dividing the specific heat release rate of the material by the heating rate used in the test (Kelvin per second) gives a flammability parameter with the units $\left(\mathrm{J} / \mathrm{g}^{-1} \mathrm{~K}\right)$ and significance of a heat release capacity (HRC), which is a good predictor of flammability. Calibration data was obtained from the manufacturer for the MCC and TGA and the measurements were very repeatable. This resulted in an estimate of $\pm 11 \%$ and $\pm 11 \%$ total expanded uncertainty for the MCC and TGA respectively. However, the repeatability of the residue and PHRR measurements for the MCC was less accurate per sample which resulted in a total expanded uncertainty of $\pm 15 \%$ and $\pm 91 \%$ respectively.

The uncertainty in coating composition includes the concentration of each material that makes up the total composition of the coating and the resulting mass gain of the substrate the coating is applied to. Each coating will have uncertainties where the concentrations are estimates since there will always be byproducts or trace amounts of solvent or unbonded materials. This resulted in an estimate of $\pm 11 \%$ and $\pm 21 \%$ total expanded uncertainty for coating concentration and mass gain respectively.

The components of calibration uncertainty for a mass balance include accuracy, sensitivity, repeatability, rounding error, eccentricity, and temperature characteristics. There is also random uncertainty due to aging over time of the mass balance and the changing atmospheric pressure during calibration. Uncertainty is also influenced by the condition of the electronic balance and the environment during calibration, so it is necessary to estimate the uncertainty of the actual instrument under the calibration environment. Therefore, the calibration uncertainties provided by the manufacturer in Table 4 are estimated calibration uncertainties using the actual instrument and are not guaranteed values. This resulted in an estimate of $\pm 11 \%$ total expanded uncertainty for the mass balance. 
Table 4: Uncertainty in experimental data.

\begin{tabular}{|c|c|c|c|c|}
\hline Instrument & $\begin{array}{l}\text { Uncertainty } \\
\text { Category }\end{array}$ & $\begin{array}{c}\text { Component Standard } \\
\text { Uncertainty }\end{array}$ & $\begin{array}{c}\text { Combined Standard } \\
\text { Uncertainty }\end{array}$ & $\begin{array}{c}\text { Total Expanded } \\
\text { Uncertainty }\end{array}$ \\
\hline \multirow{12}{*}{ TGA } & Mass Loss & $\pm 2 \%$ & \multirow{3}{*}{ $\pm 5 \%$} & \multirow{3}{*}{ $\pm 11 \%$} \\
\hline & Repeatability & $\pm 5 \%$ & & \\
\hline & Random & $\pm 3 \%$ & & \\
\hline & Temperature & $\pm 2 \%$ & \multirow{3}{*}{ $\pm 5 \%$} & \multirow{3}{*}{ $\pm 11 \%$} \\
\hline & Repeatability & $\pm 5 \%$ & & \\
\hline & Random & $\pm 3 \%$ & & \\
\hline & Char Yield & $\pm 2 \%$ & \multirow{3}{*}{ $\pm 5 \%$} & \multirow{3}{*}{ $\pm 11 \%$} \\
\hline & Repeatability & $\pm 5 \%$ & & \\
\hline & Random & $\pm 3 \%$ & & \\
\hline & Calibration & $\pm 1 \%$ & \multirow{3}{*}{ $\pm 5 \%$} & \multirow{3}{*}{ $\pm 11 \%$} \\
\hline & Repeatability & $\pm 5 \%$ & & \\
\hline & Random & $\pm 3 \%$ & & \\
\hline \multirow{18}{*}{ MCC } & HRR & $\pm 2 \%$ & \multirow{3}{*}{ $\pm 5 \%$} & \multirow{3}{*}{ $\pm 11 \%$} \\
\hline & Repeatability & $\pm 5 \%$ & & \\
\hline & Random & $\pm 3 \%$ & & \\
\hline & THR & $\pm 2 \%$ & \multirow{3}{*}{ $\pm 5 \%$} & \multirow{3}{*}{ $\pm 11 \%$} \\
\hline & Repeatability & $\pm 5 \%$ & & \\
\hline & Random & $\pm 3 \%$ & & \\
\hline & PHRR & $\pm 2 \%$ & \multirow{3}{*}{ $\pm 45 \%$} & \multirow{3}{*}{ $\pm 91 \%$} \\
\hline & Repeatability & $\pm 45 \%$ & & \\
\hline & Random & $3 \%$ & & \\
\hline & Temperature & $\pm 2 \%$ & \multirow{3}{*}{ $\pm 5 \%$} & \multirow{3}{*}{ $\pm 11 \%$} \\
\hline & Repeatability & $\pm 5 \%$ & & \\
\hline & Random & $\pm 3 \%$ & & \\
\hline & Residue & $\pm 2 \%$ & \multirow{3}{*}{ $\pm 7 \%$} & \multirow{3}{*}{ $\pm 15 \%$} \\
\hline & Repeatability & $\pm 7 \%$ & & \\
\hline & Random & $\pm 3 \%$ & & \\
\hline & Calibration & $\pm 1 \%$ & \multirow{3}{*}{ $\pm 5 \%$} & \multirow{3}{*}{ $\pm 11 \%$} \\
\hline & Repeatability & $\pm 5 \%$ & & \\
\hline & Random & $\pm 3 \%$ & & \\
\hline \multirow{6}{*}{$\begin{array}{l}\text { Coating } \\
\text { Composition }\end{array}$} & Concentration & $\pm 1 \%$ & \multirow{3}{*}{ $\pm 5 \%$} & \multirow{3}{*}{ $\pm 11 \%$} \\
\hline & Repeatability & $\pm 5 \%$ & & \\
\hline & Random & $\pm 3 \%$ & & \\
\hline & Mass Gain & $\pm 10 \%$ & & \\
\hline & Repeatability & $\pm 10 \%$ & $\pm 10 \%$ & $\pm 21 \%$ \\
\hline & Random & $\pm 3 \%$ & & \\
\hline & Zero & $\pm 1 \%$ & & \\
\hline & Repeatability & $\pm 5 \%$ & $\pm 5 \%$ & $\pm 11 \%$ \\
\hline Mass Balance & Random & $\pm 3 \%$ & & \\
\hline & Calibration & $\pm 5 \%$ & & \\
\hline & Repeatability & $\pm 5 \%$ & $\pm 5 \%$ & $\pm 11 \%$ \\
\hline & Random & $\pm 3 \%$ & & \\
\hline
\end{tabular}

Notes: 1. Random and repeatability evaluated as Type A, other components as Type B. 


\section{Conclusions and Future Work}

Aqueous-based amphiphile solutions have been co-formulated with potentially alternative flame retardants in a single bath process to make flame retardant gel coatings for cotton fabrics. Coatings containing an amphiphilic block copolymer in aqueous solution and formulated with melamine and SHMP on cotton fabrics are self-extinguishing as assessed by vertical flame testing. Coatings with higher compositions ( $20 \%$ to $25 \%$ ) of the amphiphile led to lower flame resistance hence the $15 \%$ F127 composition was used throughout for the subsequent analyses. Flame retardant effectiveness of the coatings were probed with micro-scale combustion calorimetry (MCC) and thermogravimetric analysis (TGA). The most successful performing gel formulation was $15 \%$ F127/15 \% melamine/15 \% SHMP which produced $69 \mathrm{~W} / \mathrm{g} \pm 5 \mathrm{~W} / \mathrm{g}$ in PHRR (a $61 \%$ reduction), and $9.0 \mathrm{~kJ} / \mathrm{g} \pm 1 \mathrm{~kJ} / \mathrm{g}$ in THR (a $16 \%$ reduction) of cotton combustion. The gel coatings are too thick to be commercially viable. The coated fabric also turned white due to the formulation of melamine polyphosphate. The overall hand of the fabric after coating felt stiffer and heavier compared to the soft and stretchy feel prior to coating. SEM imaging showed a uniform back-coating over all of the cotton fibers for the $15 \%$ F127/15 \% melamine/15 \% SHMP coating. The thicker gel coating showed evidence of cracks but that alone could have been a function of the higher coating film thickness. Future work is needed to explore the stability and durability of the coating after washing. Overall, the scheme for using precursors that result in the formation of a solid phase, insoluble flame retardant in a coating seems valid, although larger amounts of qualification testing and better tools to provide for a thinner and more controlled thickness are appropriate.

\section{References}

[1] Ahrens M, Home structure fires, National Fire Protection Association, 2015.

[2] Wu W, Yang CQ, Comparison of different reactive organophosphorus flame retardant agents for cotton. Part II: Fabric flame resistance performance and physical properties, Polymer Degradation and Stability, 2007;92: 363-69.

[3] Wakelyn PJ, Bertoniere NR, French AD, Thibodeaux DP, Triplett BA, Rousselle M-A, Wilton R. Goynes J, Edwards JV, Hunter L, McAlister DD, Gamble GR, Cotton Fiber Chemistry and Technology, CRC Press (Taylor and Francis Group), Boca-Raton, Florida, 2007.

[4] Carr CM, Chemistry of the Textiles Industry, Springer-Science+Business Media, B.V., 1995. [5] Li Y-C, Schulz J, Mannen S, Delhom C, Condon B, Chang S, Zammarano M, Grunlan JC, Flame retardant behavior of polyelectrolyte-clay thin film assemblies on cotton fabric, ACS Nano, 2010;4: 3325-37.

[6] Lessan F, Montazer M, Moghadam MB, A novel durable flame-retardant cotton fabric using sodium hypophosphite, nano TiO2 and maleic acid, Thermochimica Acta, 2011;520: 48-54. [7] Mostashari SM, Zanjanchi MA, Burning of a cotton fabric impregnated by synthetic zinc carbonate hydroxide as a flame retardant, Combustion, Explosion, and Shock Waves, 2005;41: 426-29.

[8] Reddy PRS, Agathian G, Kumar A, Ionizing radiation graft polymerized and modified flame retardant cotton fabric, Radiation Physics and Chemistry, 2005;72: 511-16. 
[9] Wu W, Yang CQ, Correlation between limiting oxygen index and phosphorus/nitrogen content of cotton fabrics treated with a hydroxy-functional organophosphorus flame-retarding agent and dimethyloldihydroxyethyleneurea, Journal of Applied Polymer Science, 2003;90: 1885-90.

[10] Yang CQ, He Q, Applications of micro-scale combustion calorimetry to the studies of cotton and nylon fabrics treated with organophosphorus flame retardants, Journal of Analytical and Applied Pyrolysis, 2011;91: 125-33.

[11] Martin C, Ronda JC, Cadiz V, Boron-containing novolac resins as flame retardant materials, Polymer Degradation and Stability, 2006;91: 747-54.

[12] Horrocks AR, Davies PJ, Kandola BK, Alderson A, The potential for volatile phosphoruscontaining flame retardants in textile back-coatings, Journal of Fire Sciences, 2007;25: 523-40. [13] Alaee M, Arias P, Sjodin A, Bergman A, An overview of commercially used brominated flame retardants, their applications, their use patterns in different countries/regions and possible modes of release, Environment International, 2003;29: 683-89.

[14] Sather JM, Richards HR, Efficiency of phosphorus-containing compounds for inhibiting afterglow in cellulose fabrics, American Dyestuff Reporter, 1970;59: 21-26.

[15] Leistner M, Abu-Odeh AA, Rohmer SC, Grunlan JC, Water-based chitosan/melamine polyphosphate multilayer nanocoating that extinguishes fire on polyester-cotton fabric, Carbohydrate Polymers, 2015;130: 227-32.

[16] Decher G, Schlenoff JB, Multilayer thin films, Wiley-VCH Verlag Cmbh \& Co. KGaA, 2003.

[17] Hammond PT, Form and function in multilayer assembly: new applications at the nanoscale, Advanced Materials, 2004;16: 1271-93.

[18] Bertrand P, Jonas A, Laschewsky A, Legras R, Ultrathin polymer coatings by complexation of polyelectrolytes at interfaces: suitable materials, structure and properties, Macromolecular Rapid Communications, 2000;21: 319-48.

[19] Alongi J, Carosio F, All-inorganic intumescent nanocoating containing montmorillonite nanoplatelets in ammonium polyphosphate matrix capable of preventing cotton ignition, Polymers, 2016;8.

[20] Alongi J, Carosio F, Kiekens P, Recent advances in the design of water based-flame retardant coatings for polyester and polyester-cotton blends, Polymers, 2016;8.

[21] Lvov Y, Ariga K, Ichinose I, Kunitake T, Assembly of multicomponent protein films by means of electrostatic layer-by-layer adsorption, Journal of American Chemical Society, 1995;117: 6117-23.

[22] Sato M, Sano M, Van der waals layer-by-layer construction of a carbon nanotube 2D network, Langmuir, 2005;21: 11490-94.

[23] Podsiadlo P, Kaushik aK, Shim BS, Agarwal A, Tang Z, Waas AM, Arruda EM, Kotov NA, Can nature's design be improved upon? High strength, transparent nacre-like nanocomposites with double network of sacrificial cross links, Journal of Physical Chemistry B, 2008;112: 14359-63.

[24] Zhang H, Wang Z, Zhang Y, Zhang X, Hydrogen-bonding-directed layer-by-layer assembly of poly(4-vinylpyridine) and Poly(4-vinylphenol): effect of solvent composition on multilayer buildup, Langmuir, 2004;20: 9366-70.

[25] Bai S, Wang Z, Zhang X, Hydrogen-bonding-directed layer-by-layer films: effect of electrostatic interaction on the microporous morphology variation, Langmuir, 2004;20: 1182832. 
[26] Jang W-S, Grunlan JC, Robotic dipping system for layer-by-layer assembly of multifunctional thin films, Review of Scientific Intruments, 2005;76.

[27] Gamboa D, Priolo MA, Ham A, Grunlan JC, Note: Influence of rinsing and drying routines on growth of multilayer thin films using automated deposition system, Review of Scientific Intruments, 2010;036103.

[28] Porcel CH, Izquierdo A, Ball V, Decher G, Voegel JC, Schaaf P, Ultrathin coatings and (poly(glutamic acid)/polyallylamine) films deposited by continuous and simultaneous spraying, Langmuir, 2005;21: 800-02.

[29] Krogman KC, Lowery JL, Zacharia NS, Rutledge GC, Hammond PT, Spraying asymmetry into functional membranes layer-by-layer, Nature Materials, 2009;8.

[30] Walton MD, Kim YS, Jan CJ, McConnel EP, Everett WN, Grunlan JC, Deposition and patterning of conductive carbon black thin films, Synthetic Metals, 2007;157: 632-39.

[31] Everett WN, Jan CJ, Sue HJ, Grunlan JC, Micropatterning and impedance characterization of an electrically percolating layer-by-layer assembly, Electroanalysis, 2007;19: 964-72.

[32] DeLongchamp DM, Hammond PT, Highly ion conductive poly(ethlene oxide)-based solid polymer electrolytes from hydrogen bonding layer-by-layer assembly, Langmuir, 2004;20: 540311.

[33] Hiller JA, Mendelsohn JD, Rubner MF, Reversibly erasable nanoporous anti-reflection coatings from polyelectrolyte multilayers, Nature Materials, 2002;1.

[34] Wu Z, Nolte A, Walish J, Zhai L, Rubner M, Cohen R, Layer-by-layer assembled nanoparticles on flexible substrates: toward deformable anti-reflection coatings, Polymeric Materials Science, 2005.

[35] Priolo MA, Gamboa D, Holder KM, Grunlan JC, Super gas barrier of transparent polymerclay multilayer ultrathin films, Nano Letters, 2010;10: 4970-74.

[36] Yang Y-H, Haile M, Park YT, Malek FA, Grunlan JC, Super gas barrier of all-polymer multilayer thin films, Macromolecules, 2011;44: 1450-59.

[37] Cain AA, Murray S, Holder KM, Nolen CR, Grunlan JC, Intumescent nanocoating extinguishes flame on fabric using aqueous polyelectrolyte complex deposited in single step, Macromolecular Materials and Engineering, 2014;299: 1180-87.

[38] Davis R, Li Y-C, Gervasio M, Luu J, Kim YS, One-pot, bioinspired coactings to reduce the flammability of flexible polyurethane foams, ACS Applied Materials Interfaces, 2015;7: 6082-

92.

[39] Panel CIRE, Final report on the safety assessment of sodium metaphosphate, sodium trimetaphosphate, and sodium hexametaphosphate, International Journal of Toxicology, 2001;20: 75-89.

[40] Skinner CG, Thomas JD, Osterloh JD, Melamine Toxicity, Journal of Medical Toxicology, 2010;6: 50-55.

[41] Tompkin RB, Indirect antimicrobial effects in foods: phosphates, Journal of Food Safety, 1983;6: 13-27.

[42] Mast RW, Jeffcoat AR, Sadler BM, Kraska RC, Friedman MA, Metabolism, disposition and excretion of $\left[{ }^{14} \mathrm{C}\right]$ melamine in male fischer 344 rats, Food and Chemical Toxicology, 1983;21: 807-10.

[43] Desai SD, Blanchard J, In vitro evaluation of pluronic F127-based controlled-release ocular delivery systems for pilocarpine, Journal of Pharmaceutical Sciences, 1998;87.

[44] Miyazaki S, Tobiyama T, Takada M, Attwood D, Percutaneous absorption of indomethacin from pluronic F127 gels in rats, Journal of Pharmacy and Pharmacology, 1995;47: 455-57. 
[45] Lau BK, Wang Q, Sun W, Li L, Micellization to gelation of a triblock copolymer in water: thermoreversibility and scaling, Journal of Polymer Science B: Polymer Physics, 2004;42: 201425.

[46] Wanka G, Hoffmann H, Ulbricht W, Phase diagrams and aggregation behavior of poly(oxyethylene)-poly(oxypropylene)-poly(oxyethlene) triblock copolymers in aqueous solutions, Macromolecules, 1994;27: 4145-59.

[47] Wanka G, Hoffmann H, Ulbricht W, The aggregation behavior of poly-(oxyethylene)-poly(oxypropylene)-poly-(oxyethylene)-block-copolymers in aqueous solution, Colloid Polymer Science, 1990;268: 101-17.

[48] Schmolka IR, Artificial skin I. preparation and properties of pluronic F-127 gels for treatment of burns, Journal of Biomedical Materials Research, 1972;6: 571-82.

[49] Meznarich NAK, Juggernauth KA, Batzli KM, Love BJ, Structural changes in PEO-PPOPEO gels induced by methylparaben and dexamethasone observed using time-resolved SAXS, Macromolecules, 2011;44: 7792-98.

[50] Lam Y-M, Goldbeck-Wood G, Mesoscale simulation of block copolymers in aqueous solution: parameterisation, micelle growth kinetics and the effect of temperature and concentration morphology, Polymer, 2003;44: 3593-605.

[51] Barba AA, d'Amore M, Grassi M, Chirico S, Lamberti G, Titomanlio G, Invenstigation of pluronic F127-water solutions phase transitions by DSC and dielectric spectroscopy, Journal of Applied Polymer Science, 2009;114: 688-95.

[52] Mortensen K, Batsberg W, Hvidt S, Effects of PEO-PPO diblock impurities on the cubic structure of aqueous PEO-PPO-PEO micelles: fcc and bcc ordered structures in F127 Macromolecules, 2008;41: 1720-27.

[53] Jian J, Burger C, Li C, Li J, Lin MY, Colby RH, Shear-induced layered structure of polymeric micelles by SANS, Macromolecules, 2007;40: 4016-22.

[54] Zhu P, Sui S, Wang B, Sun K, Sun G, A study of pyrolysis and pyrolysis products of flameretardant cotton fabrics by DSC, TGA, and PY-GC-MS, Journal of Analytical and Applied Pyrolysis, 2004;71: 645-55.

[55] Taylor BN, Kuyatt CE, Guidlines for Evaluating and Expressing the Uncertainty of NIST Measurement Results, NIST Technical Note 1297, 1994. 